\title{
Contextual associations in trace conditioning
}

\author{
NANCY A. MARLIN \\ University of Missouri, Rolla, Missouri 65401
}

\begin{abstract}
Rats were given tone-footshock pairings with a $0-, 10-$, or 30-sec trace interval between tone offset and shock onset. Half the rats within each trace interval were tested for their conditioned fear of the tone through a lick suppression procedure; the remaining rats were evaluated for their fear of the background or contextual cues through their avoidance of the compartment in which conditioning had occurred. Less conditioning was observed to the tone with increasing trace intervals. However, conditioned fear of the context increased with increases in the trace duration. The ability of the more predictive stimulus, the tone, to overshadow the contextual cues was determined by the tone's temporal contiguity with the footshock. The need to incorporate temporal parameters within current theories of conditioning is discussed.
\end{abstract}

The role of contextual cues in a learning situation and the associative strength that such contextual cues may acquire have recently received increased recognition. This trend is evident in studies of both animal learning (Bolles \& Collier, 1976; Bouton \& Bolles, 1979a, 1979b; Dweck \& Wagner, 1970; Pearce \& Hall, 1979; Tomie, $1981)$ and animal memory processes (Deweer, Sara, \& Hars, 1980; Grant, 1980; Hickis, Robles, \& Thomas, 1977; Spear, 1978; Spear, Smith, Bryan, Gordon, Timmons, \& Chiszar, 1980).

There are some learning procedures, such as those involving unsignaled US presentations, in which the context itself might be expected to serve as the most reliable predictor of the reinforcement (Fanselow, 1980; Marlin \& Miller, 1981; Wagner, 1976). More commonly in classical conditioning, however, a discrete $\mathrm{CS}$ is presented that conveys some information concerning the US occurrence. Given that this nominal CS occurs in an experimental background, or context, the CS ought to be expected to compete with the context for the associative strength that the particular US will support (Rescorla \& Wagner, 1972). An increasing number of experiments provide evidence of this competitive relationship. For example, Odling-Smee (1975b) varied the probability that an aversive US would be signaled by a nominal $\mathrm{CS}$ in the black compartment of a two-compartment apparatus in which one compartment was black and the other compartment was white. Following training, animals with high probabilities of receiving unsignaled USs displayed significantly greater avoidance of this initially preferred black compartment than did subjects for whom all or most USs were pre-

This research was supported by a Weldon Springs Faculty Development grant from the University of Missouri. I wish to thank Mark Bouton and Michael Fanselow for their comments on an earlier draft of this manuscript and Theresa Hedrick for her assistance in the data collection. Reprints may be obtained from Nancy A. Marlin, Department of Psychology, University of Missouri-Rolla, Rolla, Missouri 65401. ceded by a CS. The CS apparently overshadowed the background stimuli in these latter groups.

One situation in which such competition for associative strength between the nominal CS and the context would be expected to occur is trace conditioning. The observed temporal gradient for trace conditioning is, of course, highly dependent upon the response system being monitored. In the case of the rabbits' nictitating membrane response, interstimulus intervals (ISIs) approaching $4 \mathrm{sec}$ are generally ineffective (Gormezano, 1972), whereas in conditioned taste aversions, ISIs of several hours' duration are necessary for a trace conditioning deficit to become evident (cf. Logue, 1979). Moreover, the temporal parameters for successful trace conditioning may be extended by various techniques (Bolles, Collier, Bouton, \& Marlin, 1978; Kehoe, Gibbs, Garcia, \& Gormezano, 1979; Kaplan \& Hearst, Note 1). Nevertheless, given the appropriate temporal parameters, the greater the trace duration-the ISI between CS offset and US onset - the weaker is the conditioning to the nominal CS.

The Pavlovian interpretation for this trace conditioning deficit is that the effective CS consists of the pattern of afferent activity immediately preceding US onset (Pavlov, 1927). Accordingly, if the afferent activity rapidly peaks and then wanes as the CS becomes temporally more removed from the US, the afferent activity of the CS should be weaker at the moment of US onset. Conversely, given that the contextual cues ordinarily occupy the trace interval, the afferent activity reflecting the context would be more likely to be present at the US onset, such that as the trace interval increases in duration there ought to be less conditioning to the CS but greater conditioning to the background stimuli. This prediction is also consistent with more contemporary theories of classical conditioning such as the Rescorla-Wagner model (Rescorla \& Wagner, 1972). According to this model, the nominal CS and the contextual cues are each considered to be components of a compound stimulus, and, as such, the associative 
strength accruing to each component will depend upon its salience and validity relative to that of the other component of the compound.

Contextual associations in trace conditioning have recently been investigated by Odling-Smee (1975a). In that study, trace intervals for fear conditioning were manipulated factorially with CS duration. No difference in contextual associations was observed as a function of the trace interval; however, the failure to obtain differences in contextual conditioning may have been due to the use of a very narrow range of trace durations. The maximum ISI employed by Odling-Smee (1975a) was $3 \mathrm{sec}$, which is a relatively short trace for fear conditioning.

The present experiment, which used the method developed by Odling-Smee for assessing contextual associations, expanded the range of trace intervals used during conditioning. Additionally, the present study included a measure of conditioning to the nominal CS. Although it appears reasonable to infer that the nominal CS has overshadowed the context when contextual conditioning in groups receiving a CS is less than that of a group not receiving a nominal $\mathrm{CS}$ during acquisition (e.g., Odling-Smee, 1975a, 1978), it would also be desirable to measure conditioning to the nominal CS. In this way it could be established that changes in contextual conditioning were indeed accompanied by the predicted changes in conditioning to the nominal CS.

\section{METHOD}

\section{Subjects}

Seventy-two Sprague-Dawley-derived adult male rats (Charles River Co.), weighing between 246 and $589 \mathrm{~g}$, served as subjects. They were housed individually in wire mesh cages in a colony room maintained on a 12/12-h light/dark cycle. They were maintained on an ad-lib Purina Laboratory Chow diet and a 23.5 h water-deprivation schedule. Animals had been placed on this water-deprivation schedule 3 days before the beginning of the experiment. During the study, they were watered approximately $1 \mathrm{~h}$ after completion of the experimental treatment. All subjects had been adapted to handling prior to the study. Animals were assigned randomly to eight groups $(n=9)$.

\section{Apparatus}

Training for all animals occurred in a two-compartment Plexiglas apparatus with a floor made of $.64-\mathrm{cm}$-wide metal grids spaced $1.27 \mathrm{~cm}$ apart. Each compartment measured $30 \mathrm{x}$ $10 \times 15 \mathrm{~cm}$, and the compartments were separated by a removable Plexiglas door. Both compartments were identical except that the walls were white in one compartment and black in the other. The ceiling of the apparatus was clear Plexiglas and was perforated to allow for CS delivery. Each pair of adjacent metal grids in the black compartment was connected by an NE-2H neon bulb such that each grid could be electrified with respect to every other grid by the $5,000-\mathrm{V}$ shock source.

A second apparatus was used to measure lick suppression to the CS. This lick apparatus was a $30 \times 25 \times 23 \mathrm{~cm}$ enclosure made of Plexiglas with a floor of $.32-\mathrm{cm}$-wide metal grids $\mathrm{sp}_{\mathrm{i}}{ }^{-a d}$ $1.27 \mathrm{~cm}$ apart. A circular opening $1 \mathrm{~cm}$ in diameter was centerc. in a side wall $1.9 \mathrm{~cm}$ above the grid floor. A water tube connected to a lickometer circuit protruded $1 \mathrm{~cm}$ beyond the wall through this opening. This lick apparatus was enclosed in a sound-attenuating chamber.

\section{Procedure}

Training and testing took place over 3 consecutive days. All procedures occurred at approximately the same time of day during the light portion of the light/dark cycle. On Day 1, each water-deprived rat was individually placed in the lick apparatus and was allowed to find the water tube. One minute after emitting its first lick, the rat was removed from the apparatus and returned to its home cage. Day 2 consisted of a spatial preference test followed by fear conditioning in the twocompartment apparatus. Each rat was placed in the white compartment facing the open intercompartmental door and was permitted to explore the entire apparatus for $5 \mathrm{~min}$. The total time the rat spent in each compartment, as defined by the location of its hind paws, was recorded as a measure of initial preference. Immediately following this 5 -min preference test, the rat was placed in the black compartment and the intercompartmental door was closed. Each rat then received 10 presentations of a $.5-\mathrm{sec} .5-\mathrm{mA}$ constant-current footshock with a mean intershock interval of $75 \mathrm{sec}$. For six of the eight groups, the footshock was preceded by a $5-\mathrm{sec} 1,600-\mathrm{Hz} 77-\mathrm{dB}\left(\right.$ re $20 \mu \mathrm{N} / \mathrm{m}^{2}$ ) tone. (The background noise level in the apparatus was $57 \mathrm{~dB}$; all sound intensities were calibrated using the A-scale of a General Radio Sound Level Meter 1565-B.) Two groups had a 0 -sec trace interval such that CS (tone) offset was simultaneous with US (shock) onset, two groups received a 10-sec trace interval between CS offset and US onset, and two groups received a $30-\mathrm{sec}$ trace interval on all trials. The remaining two groups received only the US; they were never presented with the CS during training. Following training, the intercompartmental door was opened and subjects were again allowed to explore the apparatus for $5 \mathrm{~min}$. This interval was used because of Odling. Smee's observation $(1975 a, 1975 b, 1978)$ that it served to reduce freezing on the test trial.

On Day 3, one group $(n=9)$ of each trace interval and one of the no-CS groups (these four groups will be referred to as preference groups) were tested for their fear of the black compartment by a spatial preference test. This test was conducted in the same manner as the initial preference test on Day 2. The remaining groups of each trace interval, and the other half of the no-CS subjects, were tested for fear of the CS as measured by lick suppression and will be referred to as lick groups. Each of these rats was placed in the lick apparatus. After Lick 5 , the CS was presented and remained on continuously. The latency of animals from Lick 5-Lick 40 (in the presence of the CS) was recorded. A $900-\mathrm{sec}$ ceiling was adopted.

\section{RESULTS}

On Day 1, there were no differences among the lick groups either in their latency to Lick 1 or in their total number of licks during the 1-min lick interval $[\mathrm{Fs}(3,32) \leqslant .33]$. On Day 2 , rats in the preference groups demonstrated a strong preference for the black compartment of the two-compartment apparatus $\left[\chi^{2}(1)=23.36, p<.01\right]$. These rats spent a mean of $212.5 \mathrm{sec}$ of the 300 -sec preference test in the black compartment, and there were no differences among these groups in their initial black preference $[F(3,32) \leqslant .63]$.

Testing on Day 3 revealed differences in fear conditioning to the nominal CS and to the context as a function of the trace interval used in training (see Figure 1). In the groups tested for suppression to the CS, a trace conditioning deficit was found $[F(3,32)=11.01, p<$ $.01]$. Relative to the $0-\mathrm{sec}$ trace group, each of the other three lick groups had significantly shorter latencies from Lick 5 -Lick $40[\mathrm{ts}(16) \geqslant 2.29$, ps $<.05]$. Suppres- 


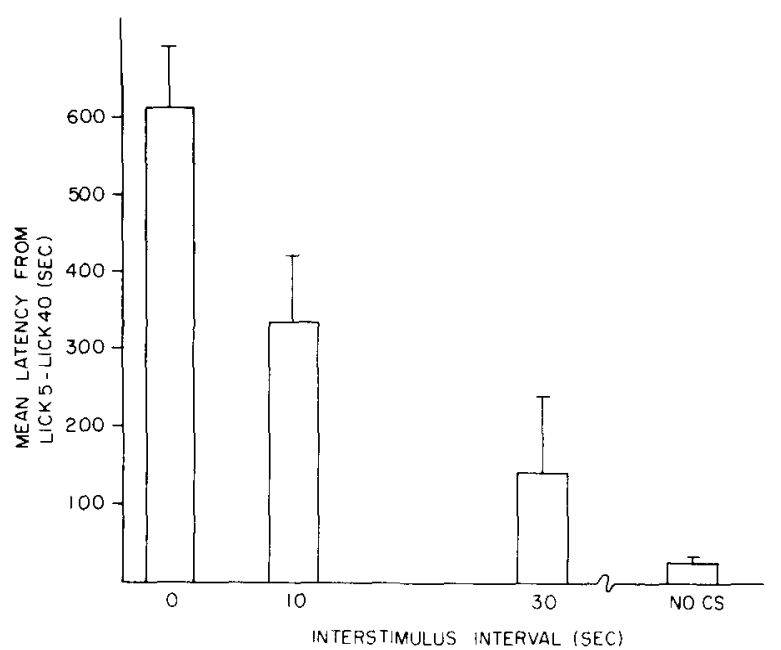

Figure 1. The mean and standard error of the test latencies of the lick groups on Day 3.

sion in the no-CS group did not differ from that observed in the $30-\mathrm{sec}$ trace group, but it was significantly less than suppression in the 0 - and $10-\mathrm{sec}$ trace conditions $[\operatorname{ts}(16) \geqslant 3.59$, ps $<.01]$. Although rats in the lick groups took longer to emit their first lick on Day 3 as compared with Day $1[\mathrm{t}(35)=3.00, \mathrm{p}<.01]$, there were no differences among the groups in their latencies to Lick 1 on either Day 1 or Day 3.

The performance of the preference groups on Day 3 is shown in Figure 2. This figure illustrates the mean number of seconds each preference group spent in the white compartment on Day 3; high scores indicate avoidance of the initially preferred black compartment in which conditioning took place. Compared with their spatial preference prior to conditioning (Day 2), neither the 0 - nor the 10-sec group showed any reliable change in their preference for the black compartment. On

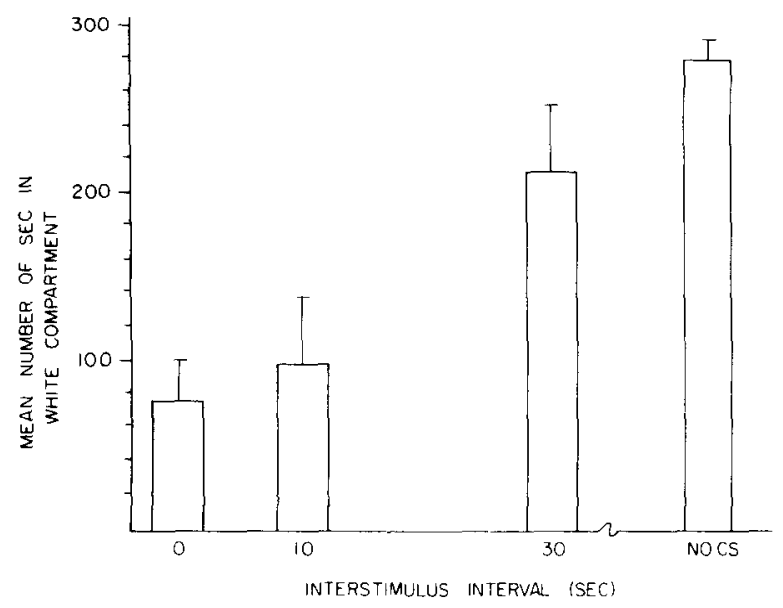

Figure 2. The mean and standard error for the number of seconds that preference groups spent in the white compartment during the 300-sec preference test on Day 3.
Day 3 , time in the white compartment differed among the preference groups $[F(3,32)=9.24, p<.01]$. The no-CS group was in the white compartment more than the 0 - or 10 -sec trace groups $[\operatorname{ts}(16) \geqslant 5.03, \mathrm{p}<.01]$ but did not differ from the 30 -sec trace group in avoidance of the black compartment. Similarly, the $30-\mathrm{sec}$ trace group spent more time in the white compartment than did the 0 -sec trace group $[\mathrm{t}(16)=2.85, \mathrm{p}<.02]$, and there was no difference between the $0-$ and 10 -sec trace groups.

\section{DISCUSSION}

The test data of the lick groups demonstrate that the temporal parameters used during conditioning produced a trace conditioning deficit. As the ISI increased, less associative strength, as indexed by lick suppression, accrued to the nominal CS. With the present parameters, this trace conditioning deficit apparently approached a maximum within $30 \mathrm{sec}$, since the 30 -sec trace group did not differ significantly from the group exposed solely to the US during acquisition. The observation of no differences in latency to begin licking on the test trial argues that the trace conditioning deficit resulted from fear of the tone rather than from differences in generalized fear among the lick groups. However, the increase in latency to begin licking from Day 1 to Day 3 suggests that a heightened level of generalized fear was present in all groups, which might perhaps be due to some generalization between the two apparatuses.

A reciprocal pattern of conditioning is seen with regard to the associative strength of the context in the preference groups. In these groups, contextual conditioning increased with increasing ISIs. When compared with the performance of the no-CS group, these data can be interpreted as representing overshadowing of the context by the CS in the 0 - and $10-\mathrm{sec}$ trace groups. Given that the context alone can clearly serve as an effective stimulus for fear conditioning (Group No CS), the presence of the $\mathrm{CS}$ reduced fear in response to the context.

These results differ from those of Hinson and Siegel (1980), who reported that a trace CS is a conditioned inhibitor. Although no reliable difference was obtained in retardation of acquisition between a group formerly given the $\mathrm{CS}$ in a trace paradigm and a group given random presentations of the CS and US prior to training, these authors did find that when the trace CS was tested in summation with a previously established excitatory $\mathrm{CS}$, the trace CS proved to be inhibitory. Probably some of the difference between the results of Hinson and Siegel (1980) and the present data reflects the use of different preparations and trace procedures. Hinson and Siegel measured the effect of a $10-\mathrm{sec}$ trace CS on eyelid conditioning in rabbits. In contrast with a conditioned emotional response such as lick suppression, eyelid conditioning is a highly specific response with relatively 
narrow temporal bounds for excitatory conditioning. Nevertheless, given a far longer trace interval, the nominal trace CS in the present experiment would presumably also become inhibitory since it would signal a shock-free interval. This prediction is analogous to the findings that, following extensive training, the beginning of a long-duration $\mathrm{CS}$ in a delay conditioning procedure becomes an inhibitory stimulus (Rescorla, 1967). Thus, despite the divergent conditioning preparations, temporal parameters, and outcomes of Hinson and Siegel (1980) and the present study, both experiments point to the operation of additional learning mechanisms during trace conditioning, suggesting that the trace conditioning deficit does not result exclusively from the passive decay of the CS.

It is likely that because of the temporal characteristics of contextual stimuli, the partitioning of associative strength between the nominal CS and the context, and the resultant overshadowing, is highly dependent upon the number of conditioning trials administered during training. Unlike typical investigations of overshadowing in which each element of the compound CS is a discrete stimulus of defined duration, contextual or background cues are necessarily always present. Therefore, with extended training, the overshadowed element of the compound, the context, may actually become inhibitory in the 0 -sec group, while in the trace conditions there may be a discrimination as to whether a particular interval of exposure to the context alone was preceded by the CS (see Bolles et al., 1978). Support for such nonmonotonic conditioned responding with increased training is evident in the elegant series of experiments by Kehoe, Gibbs, Garcia, and Gormezano (1979). They found that a serial compound CS (CS1CS2-US) was able to greatly expand the temporal interval over which the trace CS1 elicited conditioned responding of the rabbit's nictitating membrane. Although high levels of responding to CS1 with a long trace interval were obtained during the first several days of conditioning, this responding declined precipitously with continued training. The possibility that this decrease in responding may have resulted from the acquisition of inhibitory tendencies by CS1, although not tested, was suggested by these authors. The influence that contextual stimuli may have had during the trace interval in the serial compound procedure of Kehoe et al. is unknown. However, it is clear from their data and from related studies (Bolles et al., 1978; Kaplan \& Hearst, Note 1) that the use of a discrete CS2 is more successful in mediating trace conditioning to CS1 than is the context.

The continual presence of the context raises the theoretical issue of why the context acquires associative strength. Although the context is contiguous with each US, it does not provide information concerning the US occurrence within the session. Presumably, this is why the nominal CS, which is perfectly predictive of the US, is able to overshadow the contextual cues in certain conditions. The critical determinant of whether this overshadowing takes place is obviously the temporal relationship between the CS and US. Yet, this relationship poses problems for contingency models (e.g., Rescorla, 1968), since the specification of contingencies is ordinarily done by computing the $\mathrm{P}(\mathrm{US} \mid \mathrm{CS})$ and $\mathrm{P}(\mathrm{US} \mid \overline{\mathrm{CS}})$ using an arbitrary unit of time, such as the length of the CS. Using such a fixed interval of time with a trace conditioning procedure would generate an all-or-none measure of conditioning. That is, depending upon whether the CS was present within the specified time interval, the P(US|CS) would be either 1 or 0 , while the $\mathrm{P}(\mathrm{US} \mid \overline{\mathrm{CS}})$ would conversely be 0 or some constant value less than or equal to 1 . Similar problems with trace conditioning are encountered by the RescorlaWagner model in that the associative strength accruing through reinforcement and nonreinforcement of the context and the nominal CS is determined by dividing the experimental session into "trials" equal in length to the duration of the CS (Rescorla \& Wagner, 1972). To accommodate data such as those obtained in the present experiment, it is necessary to make additional assumptions regarding temporal parameters. For example, such an assumption might take the form of assigning relative weights to the salience of different time segments as a function of their contiguity with the US. Such weighting would have to reflect that the time over which the subject integrates information will likely change with experience; that is, the number of conditioning trials will interact with the functional length of the time segment. Other investigators have formulated related solutions to this problem. Bindra (1976) has suggested that the probability of the US occurring within particular fixed time intervals be combined with calculations of the conditional probability of the US occurrence. This would produce a term, the predicted imminence, that includes temporal information within a contingency model. Moore and Stickney (1980) have introduced an ISI parameter, $\tau$, that would serve as a multiplicative factor within linear model operator equations of discrepancy theories. Irrespective of which of these approaches may prove more useful, trace conditioning procedures illustrate the need to incorporate temporal parameters within current theories of classical conditioning.

In summary, the present findings complement those reported in previous research (Odling-Smee, 1975a, 1978) concerning the role of contextual cues. The observation of a learning deficit following trace conditioning is accurate if one assesses learning only to the nominal CS. Although less conditioning to the nominal CS occurs with increasing trace intervals, this is accompanied by increased conditioning to contextual or background cues. Moreover, analysis of this effect suggests that temporal contiguity-a concept that is necessarily relative to a particular conditioning preparation-is implicitly present within contemporary models of conditioning and needs to be explicitly addressed. 


\section{REFERENCE NOTE}

1. Kaplan, P., \& Hearst, E. Trace conditioning, contiguity, and context. Paper presented at the meeting of the Psychonomic Society, St. Louis, Missouri, November 1980.

\section{REFERENCES}

Bindra, D. A theory of intelligent behavior. New York: Wiley, 1976.

Bolles, R. C., \& Collien, A. C. The effect of predictive cues on freezing in rats. Animal Learning \& Behavior, 1976, 4, 6-8.

Bolles, R. C., Collier, A. C., Bouton, M. E., \& Marlin, N. A. Some tricks for ameliorating the trace-conditioning deficit. Bulletin of the Psychonomic Society, 1978, 11, 403-406.

Bouton, M. E., \& Bolles, R. C. Contextual control of the extinction of conditioned fear. Learning and Motivation, 1979, 10, 445-466. (a)

Bouton, M. E., \& Bolles, R. C. Role of conditioned contextual stimuli in the reinstatement of extinguished fear. Journal of Experimental Psychology: Animal Behavior Processes, 1979, 5, 368-378. (b)

Deweer, B., Sara, S. J., \& Hars, B. Contextual cues and memory retrieval in rats: Alleviation of forgetting by a pretest exposure to background stimuli. Animal Learning \& Behavior, $1980,8,265-272$.

DWECK, C. S., \& WAGNer, A. R. Situational cues and correlation between CS and US as determinants of the conditioned emotional response. Psychonomic Science, 1970, 18, 145-147.

Fanselow, M. S. Signaled shock-free periods and preference for signaled shock. Journal of Experimental Psychology: Animal Behavior Processes, 1980, 6, 65-80.

Gormezano, I. Investigations of defense and reward conditioning in the rabbit. In A. H. Black \& W. F. Prokasy (Eds.), Classical conditioning II: Current research and theory. New York: Appleton-Century-Crofts, 1972.

Grant, D. S. Delayed alternation in the rat: Effect of contextual stimuli on proactive interference. Learning and Motivation, 1980, 11, 339-354.

Hickıs, C. F., Robles, L., \& Thomas, D. R. Contextual stimuli and memory retrieval in pigeons. Animal Learning \& Behavior, $1977,5,161-168$.

Hinson, R. E., \& Sieget, S. Trace conditioning as an inhibitory procedure. Animal Learning \& Behavior, 1980, 8, 60-66.

Kehoe, E. J., Gibbs, C. M., Garcia, E., \& Gormezano, I. Associative transfer and stimulus selection in classical conditioning of the rabbit's nictitating membrane response to serial compounds. Journal of Experimental Psychology: Animal Behavior Processes, 1979, 5, 1-18.

Loave, A. W. Taste aversion and the generality of the laws of learning. Psychological Bulletin, 1979, 86, 276-296.

Marlin, N. A., \& Miller, R. R. Associations to contextual stimuli as a determinant of long-term habituation. Journal of Experimental Psychology: Animal Behavior Processes, 1981, 7, 313-333.

Moore, J. W., \& Stickney, K. J. Formation of attentionalassociative networks in real time: Role of the hippocampus and implications for conditioning. Physiological Psychology, 1980, 8, 207-217.

ODLING-SMEE, F. J. Background stimuli and the inter-stimulus interval during Pavlovian conditioning. Quarterly Journal of Experimental Psychology, 1975, 27, 387-392. (a)

Oduing-Smee, F. J. The role of background stimuli during Pavlovian conditioning. Quarterly Journal of Experimental Psychology, 1975, 27, 201-209. (b)

OdLing-Smee, F. J. The overshadowing of background stimuli by an informative CS in aversive Pavlovian conditioning with rats. Animal Learning \& Behavior, 1978, 6, 43-51.

Pavlov, I. P. Conditioned reflexes. London: Oxford University Press, 1927.

Pearce, J. M., \& Hall, G. The influence of context-reinforcer associations on instrumental performance. Animal Learning \& Behavior, 1979, 7, 504-508.

Rescorla, R. A. Inhibition of delay in Pavlovian fear conditioning. Journal of Comparative and Physiological Psychology, $1967,64,114-120$.

Rescorla, R. A. Probability of shock in the presence and absence of CS in fear conditioning. Journal of Comparative Psychology, 1968, 66, 1-5.

Rescorla, R. A., \& Wagner, A. R. A theory of Pavlovian conditioning: Variations in the effectiveness of reinforcement and nonreinforcement. In A. H. Black \& W. F. Prokasy (Eds.), Classical conditioning II: Current research and theory. New York: Appleton-Century-Crofts, 1972.

SpeAr, N. E. The processing of memories: Forgetting and retention. Hillsdale, N.J: Erlbaum, 1978.

Spear, N. E., Smith, G. J., Bryan, R. G., Gordon, W. C., Timmons, R., \& Chiszar, P. A. Contextual influences on the interaction between conflicting memories in the rat. Animal Learning \& Behavior, 1980, 8, 273-281.

Tomie, A. Effect of unpredictable food on the subsequent acquisition of autoshaping: Analysis of the context-blocking hypothesis. In C. M. Locurto, H. S. Terrace, \& J. Gibbon (Eds.), Autoshaping and conditioning theory. New York: Academic Press, 1981.

WAGNer, A. R. Priming in STM: An information-processing mechanism for self-generated or retrieval-generated depression in performance. In T. J. Tighe \& R. N. Leaton (Eds.), Habituation. Perspectives from child development, animal behavior, and neurophysiology. Hillsdale, N. J: Erlbaum, 1976.

(Manuscript received March 18, 1981; revision accepted for publication July 29,1981 .) 